\title{
Effects of Probiotics, Prebiotics and Synbiotics on Some Hematological and Microbiological Parameters in Laboratory Mice
}

\author{
Cristina ŞTEFĂNUŢ ${ }^{1 *}$, Laura MITREA ${ }^{1}$, Laurenţiu OGNEAN ${ }^{1}$ \\ ${ }^{1}$ Department of Animal Physiology. University of Agricultural Sciences and Veterinary Medicine \\ *Corresponding author: clcernea@yahoo.com
}

Bulletin UASVM Veterinary Medicine 72(2) / 2015,

Print ISSN 1843-5270; Electronic ISSN 1843-5378

DOI:10.15835/buasvmcn-vm: 11435

\begin{abstract}
The study aims was to visualize the effect of dietary supplements (probiotics, prebiotics, synbiotics) on clinically healthy animals and comparative analysis of hematological and microbiological parameters.

Were administered daily in four groups of five male mice (about3-4 months), probiotics - group 1 (Eubiotic $1 \mathrm{~g} / \mathrm{b} . w$. .), prebiotic - group 2 (Lactulose $0.66 \mathrm{gram} / \mathrm{kg}$ body weight), symbiotic - group 3(combination of Eubiotic and Lactulose) and distillated water - group 4 (control group). Before administration and 13 days after administration microbiological samples were taken from the rectum, hematological analyses were performed (blood cells count, white blood cells differential and blood glucose level); blood was collected from the retrobulbar sinus under anaesthesia with chloroform.

The total number of red blood cells was 3.15 and $6.3 \mathrm{~T} / \mathrm{L}$ and the WBC 3.05 and $8.25 \mathrm{G} / \mathrm{L}$ respectively. Administration of the probiotic determined stimulation of the immune system by increasing the total number of white blood cell, increasing of the number of intestinal bacterial species and decreasing of CFU. The prebiotic produced not significant changes of the parameters analysed. In the case of the symbiotic the change was due to the probiotic dose, post-treatment differences are similar to those in group 1 (treated with probiotic) but not so intense.

In the present research work, we observed that administration of pro- and prebiotics has not negatively influenced the health of animals. The probiotic produced the most significant growth rate, achieved with a superior feed conversion rate.
\end{abstract}

Keywords: hematology, mice ,prebiotics, probiotics, synbiotics,

\section{INTRODUCTION}

At level of intestine is very important the equilibrium between the intestinal microflora and the host. Many factors can affect the intestinal microbial ecology: diseases, nutrition, treatments, stress, living condition (Gibson and Fuller, 2000). For maintaining of the intestinal microflora and the health of animals, one alternative is using of probiotic, prebiotic, and synbiotic products.

Probiotics are: "live microorganisms which, when consumed in adequate amounts, confer a health benefit on the host" (Guarner and Schaafsm, 1998; FAO, 2002; Donohue, 2006).
Prebiotics can be defined as "nondigestible food ingredients that beneficially affect the host by selectively stimulating the growth and/or the activity of one or a limited number of bacterial species already resident in the colon, and thus attempt to improve host health" (Gibson and Roberfroid, 1995; Schrezenmeir, and de Vrese, 2001).

The synbiotic is a product that contains both prebiotic(s) and probiotic(s). These food supplements have numerous and complex effects on the intestinal microbiota and gut immune system (Gourbeyre et al., 2011). 
The study aims was to visualize the effect of dietary supplements (probiotics, prebiotics, synbiotics) on clinically healthy animals and comparative analysis of hematological and microbiological parameters.

\section{MATERIALS AND METHODS}

\section{Treatments}

The probiotic used was a product, which contained live bacterial cultures $-250 \times 10^{6} \mathrm{CFU}$ : Bifidobacterium BB-12, Lactobacilus paracasei 43; Streptococcus thermophilus TH4.

The prebiotic was lactulose that is a disaccharide synthetized from fructose and galactose. This substance is used for effect on the gastrointestinal system: control of gastric acidity, regulated gastrointestinal motility and water flow. Also, is able to simulate healthy intestinal microflora.

The synbiotic was the combination of probiotic and prebiotic, and was used because the symbiotic stimulate and increase the survival of probiotic and autochthonous-specific strains in the intestinal tract.

\section{Animals and protocol}

Male mice ( $\mathrm{N}=20$, age 12 weeks), were randomly divided into 4 groups: PROB, PREB, SYNB, CRLT. The administration of the products was made by gastric gavage in $0.5 \mathrm{ml}$ distillated water, daily.

In PROB-treated group, mice were treated with $0.03 \mathrm{~g}$ probiotic $\left(2.14 \times 10^{6} \mathrm{CFU} /\right.$ animal $)$. In PREB-treated group, mice received $0.01 \mathrm{~g}$ lactulose/animal. The SYNB group received 0.015 g probiotic $\left(1.7 \times 10^{6} \mathrm{CFU} /\right.$ animal $)$ in combination with $0.007 \mathrm{~g}$ lactulose/animal. The CRLT was the negative group and was administrated $0.5 \mathrm{ml}$ distillated water/animal.

Animals were kept in separate cage for each group, in a controlled environment with 12:12 light-dark cycle and ad libitum access to water and food.

Administration of products, body weight and food intake (quantity of food) were monitored every day, for 12 days.

I days 1 and 13 of the study were collected blood samples for hematology and rectal samples for microbiology.

The study was performed with the agreement of bioethics comity of Faculty of Veterinary Medicine Cluj and according with the EU regulation concerning laboratory animal welfare.

\section{Hematological analysis}

For hematological investigation, blood was collected (with heparin) from retrobulbar sinus under anesthesia with chloroform. Hematological analyzes were the following: determination of total number of erythrocytes and leucocytes, leukocyte formula and blood glucose level (Tab. 1).

\section{Microbiological analysis}

For the microbiological examination of rectal samples was used cultivation on the different culture mediums: blood agar, MacConkey agar and glucose agar. Bacteria were counted and identified hemolysis test, catalase and oxidase tests.

\section{Growth performance}

All mice were weighed individually in every day. Daily weight gain for each dietary treatment was calculated. Feed consumption was recorded in the course of the whole experiment for each treatment, and the feed conversion rate (FCR) was calculated subsequently.

\section{Statistical analysis}

Statistical analyses were conducted with the GraphPad InStat to determine if variables differed between groups. The Kolmogorov-Smirnov test was used to test the normal distribution of the data before statistical analysis was performed. Results are expressed as means \pm SD. All the investigated parameters were compared between groups by one-way ANOVA and subsequent Welch

Tab. 1 The methods used for hematological investigation

\begin{tabular}{cccc}
\hline Nr. crt & INVESTIGATED PARAMETERS & METHOD & UNIT OF \\
\hline 1. & Red Blood Cells count & Hemocytometer method & T/L \\
\hline 2. & White Blood Cells count & Hemocytometer method & G/L \\
\hline 3. & Blood glucose & Glucometer & $\mathrm{mg} / \mathrm{dl}$ \\
\hline 4. & White Blood Cells differential & Blood smears - stain DQP & $\%$ \\
\hline
\end{tabular}


test. Probability values of less than $0.05(\mathrm{P}<0.05)$ were considered significant.

\section{RESULTS AND DISCUSSION Hematological analysis}

We observed the decreasing of total number of erythrocytes (Tab. 2) to all the groups, but the level of this parameter was between physiological limits. The most important decreasing was to CRLT group, in this case the differences was significant $(\mathrm{P}<0.05)$.

We monitored the level of total number of leucocytes. The relevant difference was observed in case of administration of probiotic (PROB-group) which produced the significant increase $(\mathrm{P}<0.05)$ of total leukocytes; the level of this parameter was $3.99 \pm 1.481 \mathrm{G} / \mathrm{L}$ for first determination and $7.73 \pm 1.70 \mathrm{G} / \mathrm{L}$ for the end of the study. Also, the increasing of total leukocytes was important for SYNG-group $(3.87 \pm 1.0 \mathrm{G} / \mathrm{L}-6.66 \pm 3.0 \mathrm{G} / \mathrm{L})$ (Tab. 2). Comparative evaluation of blood glucose levels revealed significant increases (between physiological limits) for the groups PROB, PREB,
SYNB, and decreases in case of CRLT group (Tab. 2).

The leukocytes subpopulations analyze, revealed the differences between the groups at the end of the experiment. The significant change for the PROB-group was the decrease of the monocytes. In case of PREB-group, we observed the increasing of the eosinophils and the evolution for SYNB-group was characterized by the increase of the neutrophils with decreasing of monocytes (Tab. 3).

\section{Microbiological examination}

Administration of the probiotic and prebiotic produced, generally, changes in the intestinal microbial communities. In our study, in the microbial population were predominant the following bacterial species: Escherichia coli, Enterococccus faecalis, Staphylococccus spp., Micrococcus spp., Bacillus spp. At the end of the study, we observed important differences between the groups of animals and the moment of samples collection. In case of PROB-group, we observed increasing of number of bacterial species with decreasing of CFU. Increasing of bacterial species

Tab. 2 Hematological investigated parameters (average \pm SD) of the experimental group

\begin{tabular}{ccccccc}
\hline \multirow{2}{*}{ GROUPS } & \multicolumn{7}{c}{ Prythrocytes (T/L) } & \multicolumn{2}{c}{ Leucocytes (G/L) } & \multicolumn{2}{c}{ Blood glucose (mg/dl) } \\
\cline { 2 - 7 } & Day 1 & Day 13 & Day 1 & Day 13 & Day 1 & Day 13 \\
\cline { 2 - 7 } & $3.98 \pm 2.59$ & $3.53+1.99$ & $3.99 \pm 1.48$ & $7.73 \pm 1.70^{*}$ & $95.4 \pm 19.69$ & $152 \pm 37.06^{*}$ \\
\hline PROB & $4.92 \pm 0.83$ & $4.11 \pm 0.52$ & $3.93 \pm 0.64$ & $3.84 \pm 1.21$ & $106.4 \pm 20.82$ & $161.4 \pm 31.66$ \\
\hline PREB & $5.49 \pm 0.67$ & $3.82 \pm 0.73$ & $3.87 \pm 1.0$ & $6.61 \pm 3.05$ & $99 \pm 18.88$ & $123.2 \pm 27.22$ \\
\hline SYNB & $5.33 \pm 2.38$ & $3.58 \pm 1.48^{*}$ & $6.18 \pm 2.63$ & $6.32 \pm 1.81$ & $108 \pm 28.16$ & $83.25 \pm 24.49$ \\
\hline CRLT & \multicolumn{7}{c}{ PROB=probiotic; PREB=prebiotic; SYNB=synbiotic; CRLT=control; ${ }^{*}=$ significant difference $(\mathrm{p}<0.05)$} &
\end{tabular}

Tab. 3 Leucocytes formula (average \pm SD) of the experimental group

\begin{tabular}{|c|c|c|c|c|c|c|c|c|c|c|}
\hline \multirow{3}{*}{ GROUPS } & \multicolumn{10}{|c|}{ LEUCOCYTES } \\
\hline & \multicolumn{2}{|c|}{ Neutrophils (\%) } & \multicolumn{2}{|c|}{ Eozinophiles (\%) } & \multicolumn{2}{|c|}{ Basophiles (\%) } & \multicolumn{2}{|c|}{ Lymphocytes (\%) } & \multicolumn{2}{|c|}{ Monocytes (\%) } \\
\hline & Day 1 & Day 13 & Day 1 & Day 13 & Day 1 & Day 13 & Day 1 & Day 13 & Day 1 & Day 13 \\
\hline PROB & $41 \pm 2.74$ & $\begin{array}{c}47 \\
\pm 11.60\end{array}$ & $\begin{array}{c}6.8 \\
\pm 3.27\end{array}$ & $\begin{array}{c}8,6 \\
\pm 4.22\end{array}$ & 0 & 0 & $\begin{array}{c}40 \\
\pm 6.60\end{array}$ & $\begin{array}{c}36.6 \\
\pm 13.07\end{array}$ & $\begin{array}{c}11.6 \\
\pm 1.34\end{array}$ & $\begin{array}{c}7.2^{*} \\
\pm 2.17\end{array}$ \\
\hline PREB & $\begin{array}{c}38.4 \\
\pm 12.40 \\
\end{array}$ & $\begin{array}{c}49 \\
\pm 4.24 \\
\end{array}$ & $\begin{array}{c}2.6 \\
\pm 1.82 \\
\end{array}$ & $\begin{array}{c}6.8^{*} \\
\pm 3.03 \\
\end{array}$ & 0 & 0 & $\begin{array}{c}48.8 \\
\pm 10.55 \\
\end{array}$ & $\begin{array}{c}37.4 \\
\pm 2.79 \\
\end{array}$ & $\begin{array}{c}10.2 \\
\pm 4.76 \\
\end{array}$ & $\begin{array}{c}6.0 \\
\pm 1.41 \\
\end{array}$ \\
\hline SYNB & $\begin{array}{c}36.8 \\
\pm 6.76 \\
\end{array}$ & $\begin{array}{c}49^{*} \\
\pm 7.97\end{array}$ & $\begin{array}{c}6.6 \\
+2.79 \\
\end{array}$ & $\begin{array}{c}6.4 \\
\pm 3.13 \\
\end{array}$ & 0 & 0 & $\begin{array}{l}40.0 \\
\pm 2.0 \\
\end{array}$ & $\begin{array}{c}35.8 \\
\pm 7.43\end{array}$ & $\begin{array}{l}16.16 \\
\pm 4.16 \\
\end{array}$ & $\begin{array}{c}8.8^{*} \\
+2.59 \\
\end{array}$ \\
\hline CRLT & $\begin{array}{r}39.75 \\
\pm 3.30 \\
\end{array}$ & $\begin{array}{c}53.5 \\
\pm 12.12 \\
\end{array}$ & $\begin{array}{r}3.75 \\
\pm 2.22 \\
\end{array}$ & $\begin{array}{c}7.5 \\
\pm 5.69 \\
\end{array}$ & 0 & 0 & $\begin{array}{l}45.75 \\
\pm 6.99 \\
\end{array}$ & $\begin{array}{c}31^{*} \\
\pm 11.20 \\
\end{array}$ & $\begin{array}{r}45.75 \\
\pm 6.99 \\
\end{array}$ & $\begin{array}{c}8.0 \\
\pm 4.97 \\
\end{array}$ \\
\hline
\end{tabular}


Tab. 4 Feed consumption, average gain and feed conversion rate of the experimental group

\begin{tabular}{cccc}
\hline & FEED CONSUMPTION $(\mathrm{g})$ & AVERAGE GAIN $(\mathrm{g})$ & FEED CONVERSION RATE \\
\hline PROB & 295 & 34.00 & 8.68 \\
\hline PREB & 278 & 31.00 & 8.97 \\
\hline SYNB & 283 & 23.00 & 12.30 \\
\hline CRLT & 238 & 27.00 & 8.81 \\
\hline PROB=probiotic; PREB=prebiotic; SYNB=synbiotic; CRLT=control & &
\end{tabular}

is linked to the composition (bacterial structure) of probiotic product. Administration of prebiotic has caused increasing of CFU, with the maintenance of a constant level of bacterial species. The symbiotic has the same effect as the prebiotic. In case of CRLT group, the number of bacterial species and CFU were constant in the two moments of analysis (first day and last day of the study).

\section{Growth performance}

The initial body weight of mice did not differ between groups. At the end of experiment, mice treated with pro-, pre- and symbiotic has a greater body weight compared with control. Feed conversion rate (FCR) was low for PROB-group (8.68) than CRLT-group (8.81) and PREB-group (8.97) and SYNB-group (12.3) (Tab. 4).

The beneficial effects of pre-, pro-, and symbiotic products can be based on the ability to change the composition of bacterial communities in gastrointestinal tract (GIT) biofilm and on displacement of pathogenic microorganisms and/or modification of immune system reactions through different mechanisms (de Vrese and Schrezenmeir, 2008). All these effects are based on the characteristic properties of each product.

Probiotics can directly inhibit the growth of pathogens by producing antibacterial substances, including bacteriocins (such as antibiotics) and different acids (acetic, lactic, and propionic acid) (Cotter et al., 2005; Servin, 2004). They can also decrease the adhesion of pathogens and their toxins to the gastrointestinal tract through their ability to adhere to intestinal epithelial cells. Gourbeyre et al. (2011) show that probiotic bacteria can enhance the integrity of the intestinal barrier. Probiotics are able to exert an impact on the intestinal environment through different key non-immune mechanisms (Gourbeyre et al., 2011).

The principal effect of prebiotic is related to the metabolism of the microbiota (Gourbeyre et al., 2011). Prebiotics are selectively fermented ingredients that allow specific changes both in the composition and/or in the activity of gastrointestinal microflora. Their exact mechanism of action is still unclear. Apparently they are able to increase the production of small chain fatty acid (SCFA) and to modulate cytokines production within the gut mucosa, by modulating the gut flora composition (Scaldaferri et al., 2013).

A combination of probiotic(s) and prebiotic(s) constitutes a synbiotic (Gourbeyre et al., 2011; Gibson and Roberfroid, 1995; Fooks and Gibson, 2002), which can stimulate and increase the survival of probiotic and autochthonous-specific strains in the intestinal tract.

Gourbeyre et al. (2011) revealed that probiotics and prebiotics, alone or together (synbiotics), can influence the intestinal microbiota and modulate the immune response. Prebiotic and probiotic have effects on the innate and adaptive immune responses. A nonspecific effect through the stimulation of innate immune cells produced increase in the cytotoxic activity of NK cells and macrophage phagocytosis.

Generally, the growth performance and feed efficiency are induced by the total effects of proand prebiotics, including maintenance of normal ecology of intestinal microflora and increasing of feed intake and digestion (Awad et al., 2009).

\section{CONCLUSION}

The analysis of the results reveals that the administration of pro-, pre-, and synbiotic did not have negative effect on the health of animals. Also, were observed different aspects depending on the parameters investigated and experimental group:

1. The probiotic determined: stimulation of the immune system by increasing of the total number of leukocytes; increasing of intestinal bacterial species with decreasing of $\mathrm{CFU}$; the largest increase of body weight with a superior feed conversion rate. 
2. The probiotic did not cause significant changes to the investigated parameters.

3. In the case of symbiotic, the changes were due by the probiotic dose, post-treatment differences were similar to those obtained after administration of the probiotic, but not so intense.

\section{REFERENCES}

1. Awad WA, Ghareeb K, Abdel-Raheem S, Böhm J (2009). Effects of dietary inclusion of probiotic and synbiotic on growth performance, organ weights, and intestinal histomorphology of broiler chickens. Poultry Science 88:49-55.

2. Cotter P D, Hill C, Ross RP (2005). Bacteriocins: developing innate immunity for food. Nat Rev Microbiol 3:777-788.

3. De Vrese M, Schrezenmeir, J (2008). Probiotics, prebiotics, and synbiotics. Adv Biochem Eng Biotechnol 111:1-66.

4. Donohue Diana C (2006). Safety of probiotics. Asia Pac J Clin Nutr 2006 15(4):563-569.

5. Gardlik R, Palffy R, Celec P (2012). Recombinant Probiotic Therapy in Experimental Colitis in Mice. Folia Biologica (Praha) 58:238-245.

6. Gibson GR, Fuller R (2000). Aspects of In Vitro and In Vivo Research Approaches Directed Toward Identifying
Probiotics and Prebiotics for Human Use. Supplement to The Journal of Nutrition, 391S-395S.

7. Gibson GR, Roberfroi MB (1995). Dietary modulation of the human colonic microbiota: introducing the concept of prebiotics. J Nutr 125:1401-1412.

8. Gourbeyre P, Denery S, Bodinier M (2011.) Probiotics, prebiotics, and synbiotics:impact on the gut immune system and allergic reactions. Journal of Leukocyte Biology 89:685-695.

9. Guarner F, Schaafsma G J (1998). Probiotics. Int J Food Microbiol 39:237-238.

10. Scaldaferri F, Gerardi V, Lopetuso LR, Del Zompo F (2013). Gut Microbial Flora, Prebiotics, and Probiotics in IBD: Their Current Usage and Utility. BioMed Research International 2013:1-9.

11. Schrezenmeir J, de Vrese M (2001). Probiotics, prebiotics, and synbiotics-approaching a definition. Am J Clin Nutr 73:361S-364S.

12. Servin A L (2004). Antagonistic activities of lactobacilli and bifidobacteria against microbial pathogens. FEMS Microbiol Rev 28:405-440.

13. ***AO/WHO (2002). Guidelines for the evaluation of probiotics in food. Report of a Joint FAO/WHO Working Group on Drafting Guidelines for the Evaluation of Probiotics in Food. London, Ontario, Canada. FAO/WHO, April 30 and May 1, 1-11. 